\title{
OPTIMIZATION OF AN OPEN CYCLE GAS TURBINE POWER PLANT USING EXERGOECONOMICS
}

\author{
Mukesh Gupta $^{1}$ and Raj Kumar ${ }^{2}$ \\ ${ }^{1,2}$ Department of Mechanical Engineering, YMCA University of Science \& Technology \\ Faridabad, Haryana, India
}

\begin{abstract}
The purpose of current study is to analyze the performance of an open cycle gas turbine power plant using the concepts of exergoeconomics. Exergoeconomic technique involves the use of Second law of thermodynamics and assigns monetary values to the thermodynamic quantity known as exergy. Analyses based on exergoeconomic criteria are done for the open cycle gas turbine power plant turbine. The methodology is illustrated using the example of a $25 \mathrm{MW}$ open cycle gas turbine power plant. Optimization has been done for the open cycle gas turbine power plant as tradeoffs between the unit product cost of the compressor and combustion chamber as functions of compressor pressure ratio and unit product costs of combustion chamber and gas turbine as functions of turbine inlet temperature.
\end{abstract}

\section{KEYWORDS}

Exergoeconomic Evaluation, Exergetic cost, Open cycle gas turbine

\section{INTRODUCTION}

Open cycle gas turbine power plants have a significant role in the power generation industry. In India, $10.5 \%$ of the total power generated, is done using gas turbine power plants. Hence their analysis from thermodynamic and economics viewpoint is extremely important. Many researchers have analysed the performance of open cycle gas turbine power plants using the first law of thermodynamics. It uses energy as the driving factor to analyze the power plant. However, it is extremely difficult to assign cost values to energy streams entering and leaving the power plant. The current study uses the second law of thermodynamics approach to evaluate the performance of the open cycle gas turbine power plant. In this approach, exergy is the criterion to analyze the performance of the power plant and costs can be assigned to various exergy streams entering and leaving the system. Firstly cost calculations have been done for various components of the open cycle gas turbine power plant. Optimization has been done for the plant as trade offs between the unit product cost of the compressor and combustion chamber as functions of compressor pressure ratio and unit product costs of combustion chamber and gas turbine as functions of turbine inlet temperature. This study provides a strong model which can be used for analysis of open cycle gas turbine power plants from other factors as well. 
The fundamentals of the methods of exergy analysis and entropy generation and minimization have been described in detail [1]. Optimization of a single and double effect vapour absorption refrigeration system using the exergy based method has been done with good results [2, 3, 4]. Variables such as exergetic efficiency, the rates of exergy destruction, exergy destruction ratio, and the cost rates associated with exergy destruction provide a holistic view of the operation of the plant [5]. Several thermodynamic relations between the energy and exergy losses in a modern coal fired electrical generation station have been developed and used extensively in research $[6,7$, $8,9,10]$. Rational efficiencies of the modern fossil-fuel power plants using the exergy calculations have been studied in detail [11]. Exergetic efficiencies, irreversibilities, and improvement factors of a turbine, steam generator and pumps for a $2 * 160 \mathrm{MW}$ coal fired thermal power plant have been calculated. Comparison between conventional and fluidized bed power plant have been made and improving techniques have also been given for the conventional plants [12] Graphical exergy analysis has been used to locate inefficient segments in the combined cycle plant [13]. Exergy analyses has been applied to a wide range of processes including the production of hydrogen and hydrogen-derived fuels, electrical and thermal power generation, thermal energy storage, and the energy utilization of countries $[14,15,16]$. To evaluate the exergy losses in the individual components of a cogeneration system, exergy analysis for each component in the subsystems has been done [17]. Different methods to estimate the avoidable and unavoidable exergy destruction and investment costs associated with compressors, turbines, heat exchangers and combustion chambers have been described [18]. The primary way of keeping the exergy destruction, in a combustion process, within a reasonable limit is to reduce the irreversibility in heat conduction [19].

\section{METHODOLOGY}

The methodology adopted for the current study is illustrated with the flowchart given in Fig. 1.

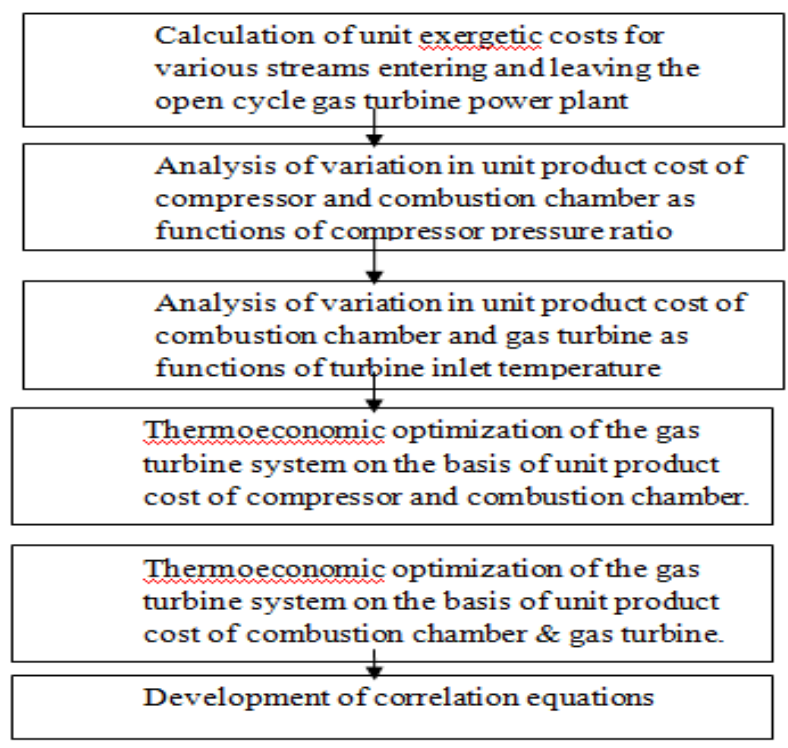

Figure 1. Flowchart depicting the methodology adopted in the current study 
In the current study, the first step is to calculate the costs associated with each stream entering and leaving the open cycle gas turbine system. Once these costs have been calculated, the next step involves analysis of variation in unit product cost of compressor and combustion chamber as a function of the compressor pressure ratio. Next we analyze the effect of turbine inlet temperature on the unit product costs of the combustion chamber and gas turbine. The next step involves optimization of the open cycle gas turbine power plant on the basis of unit product costs of compressor and combustion chamber. Finally, we optimize the system on the basis of unit product cost of combustion chamber and gas turbine.

\subsection{Open cycle gas turbine power plant}

The major streams entering and leaving an open cycle gas turbine power plant are shown in Fig. 2 .

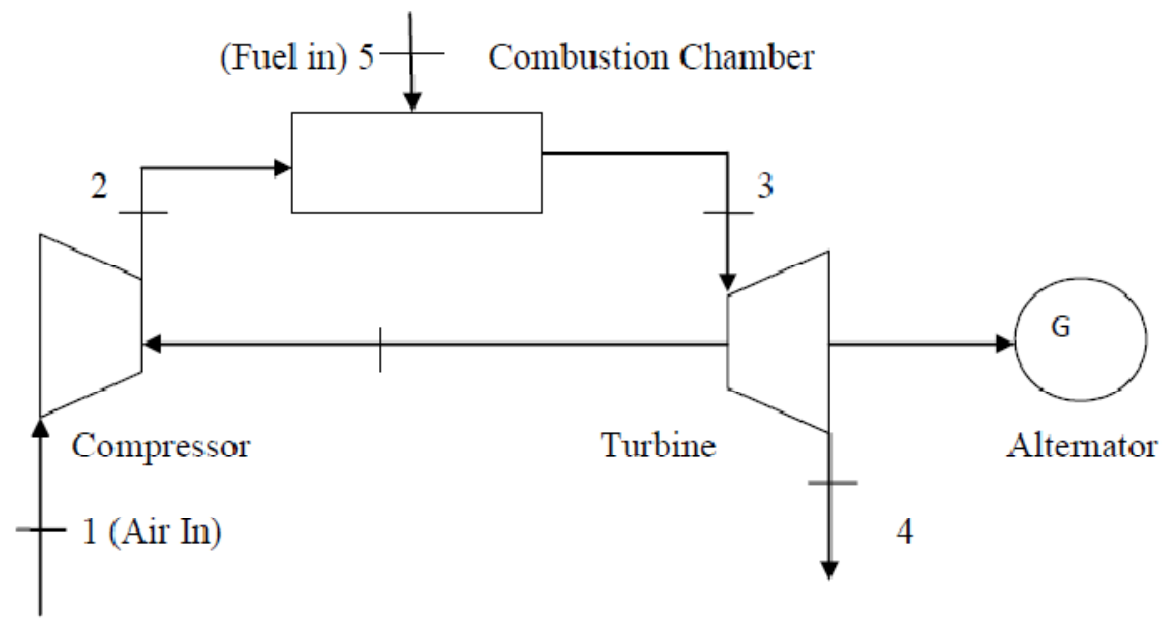

Fig. 2 Schematic layout of an open cycle gas turbine power plant

The open cycle gas turbine system comprises of a compressor, combustion chamber, gas turbine and an alternator. The compressor takes in air which is compressed to the desired pressure. The pressurized air is then fed to the combustion chamber which uses natural gas as fuel. As a result of combustion in the combustion chamber, the temperature of air is increased significantly. The high temperature products of combustion are then fed to the gas turbine, where they expand to give the desired work output. The work output from the turbine is fed to the alternator which converts it into electricity. 


\subsection{Exergoeconomic Analysis}

Unit costs per exergy unit of fuel and product for the various components of the system are given below

$$
\begin{gathered}
c_{F, T}=\frac{C_{F, T}}{E_{F, T}} \\
c_{P, T}=\frac{C_{P, T}}{E_{P, T}}
\end{gathered}
$$

The optimization process for the open cycle gas turbine power plant involves the assumption that the exergy flow rate from the power plant is constant.

The exergy costing equations, for various components of the power plant established, as per Fig. (2) are given below:

For compressor

$$
c_{1} \dot{E}_{1}+c_{w} \dot{W}_{a c}+\dot{Z}_{a c}=c_{2} \dot{E}_{2}
$$

For combustion chamber

$$
c_{2} \dot{E}_{2}+c_{5} \dot{E}_{5}+\dot{Z}_{c c}=c_{3} \dot{E}_{3}
$$

For gas turbine

$$
c_{3} \dot{E}_{3}+\dot{Z}_{g t}=c_{4} \dot{E}_{4}+c_{w} \dot{W}_{a c}+c_{w} \dot{W}_{n e t}
$$

For overall plant

$$
c_{1} \dot{E}_{1}+c_{5} \dot{E}_{5}+Z_{\text {total }}=c_{4} \dot{E}_{4}+c_{w} \dot{W}_{\text {net }}
$$

In the current study all the variables are taken as constant and the effect of compressor pressure ratio and turbine inlet temperature on the economic performance of the open cycle gas turbine power plant are analyzed. 


\section{CASE STUDY}

For analysis purpose, an open cycle gas turbine power plant of $25 \mathrm{MW}$ capacity has been considered. The system comprises of an air compressor, a combustion chamber and a gas turbine. The mass flow rate of air is $212.95 \mathrm{~kg} / \mathrm{s}$ and air enters the compressor at a temperature of $20^{\circ} \mathrm{C}$ and a pressure of 0.981 bars. The pressure increases to 4.81 bars through the compressor whose isentropic efficiency has been taken as $80 \%$. The inlet temperature to the gas turbine is $1123^{\circ} \mathrm{C}$ and a pressure of 1.01325 bars. The isentropic efficiency of the turbine has been taken as $80 \%$. The exhaust gases from the turbine are at $817^{\circ} \mathrm{C}$ and 1.10 bars. The fuel (natural gas) is injected at $20^{\circ} \mathrm{C}$ and 22 bars. For these conditions the values of costs for the power plant are given in Table 1.

Table 1. Values of costs for different streams for the open cycle gas turbine power plant

\begin{tabular}{|c|c|}
\hline Stream No. & $\begin{array}{c}\text { Unit Cost } c \\
\text { (US \$/ MW) }\end{array}$ \\
\hline 1 & 0 \\
\hline 2 & 5.146 \\
\hline 3 & 4.28 \\
\hline 4 & 4.34 \\
\hline 5 & 4.34 \\
\hline $\mathrm{c}_{\mathrm{w}}$ & 4.46 \\
\hline
\end{tabular}

\section{RESULTS AND DISCUSSION}

The first step in the exergoeconomic process is to study and analyze the effect of compressor pressure ratio on the unit product cost of the compressor and combustion chamber. It has been observed that with an increase in the compressor pressure ratio, the unit product cost of the compressor increases while the unit product cost of the combustion chamber decreases. This is shown in Fig. 3. and Fig. 4. This happens because as to operate the compressor at higher compressor pressure ratios, the operation and maintenance costs increase, thereby increasing the unit product cost of the compressor. At higher compressor pressure ratios, the unit product cost of the combustion chamber decreases as increase in compressor pressure ratio leads to the combustion mixture entering the combustion chamber at higher temperature. This results in lower fuel costs, as less fuel is required to generate the same amount of heat in the combustion chamber.

The second step is to study and analyze the variation of unit product cost of combustion chamber and gas turbine with variations in turbine inlet temperature. It has been observed that with increase in the turbine inlet temperature, unit product cost of the combustion chamber increases. This happens because high amount of fuel is needed to generate higher temperatures of products of combustion, resulting in higher unit product costs of the combustion chamber. This is shown in Fig. 5. Also, the unit product cost of the gas turbine decreases with increase in the turbine inlet temperature. This happens because an increase in the turbine inlet temperature results in the gas turbine operating at higher exergetic efficiency, thereby leading to reduction in unit product costs. This has been illustrated in Fig. 6 . 


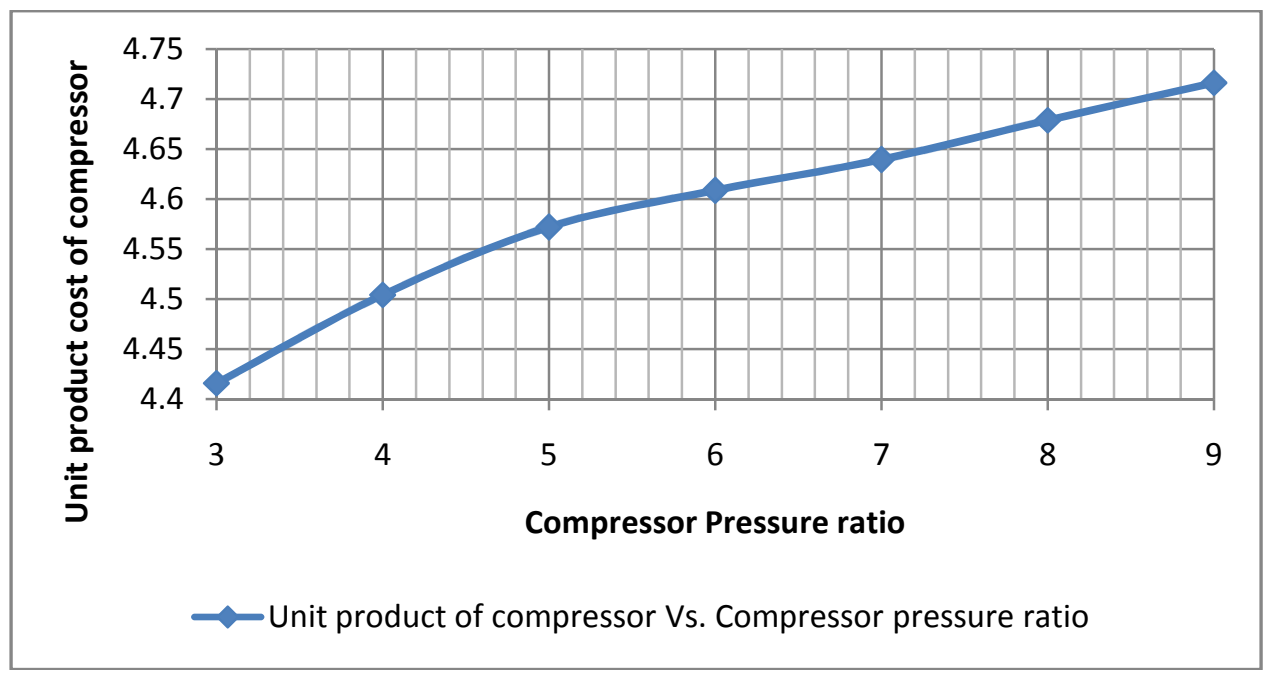

Fig. 3 Variation of unit product cost of compressor with compressor pressure ratio

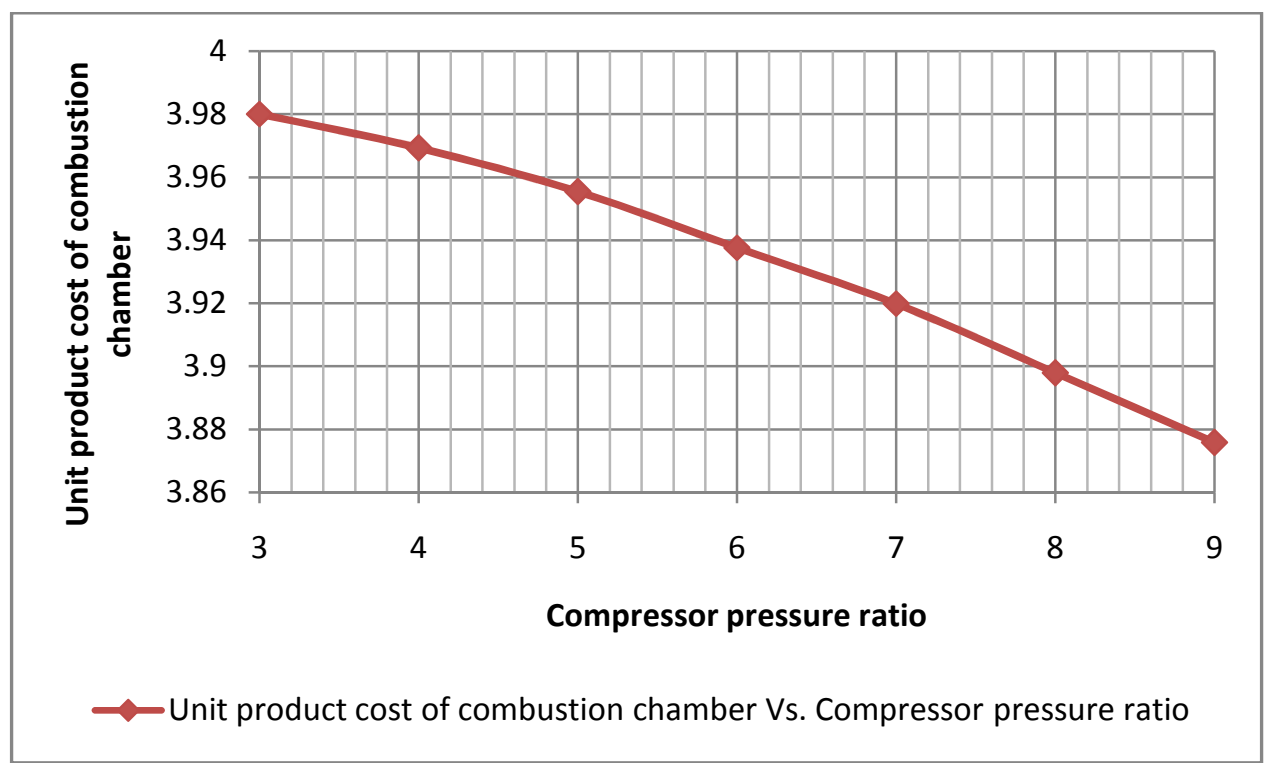

Fig. 4. Variation of unit product cost of combustion chamber with compressor pressure ratio 
International Journal of Recent advances in Mechanical Engineering (IJMECH) Vol.4, No.4, November 2015

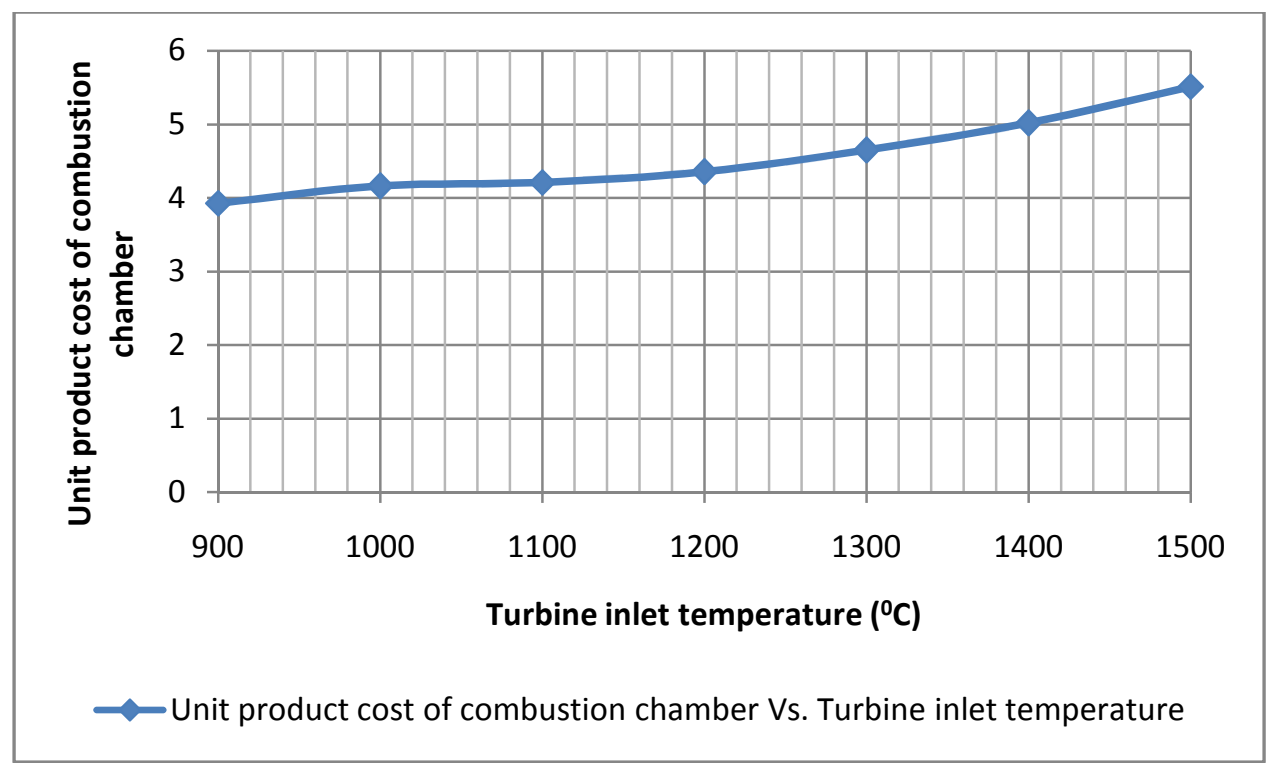

Fig. 5 Variation of unit product cost of combustion chamber with turbine inlet temperature

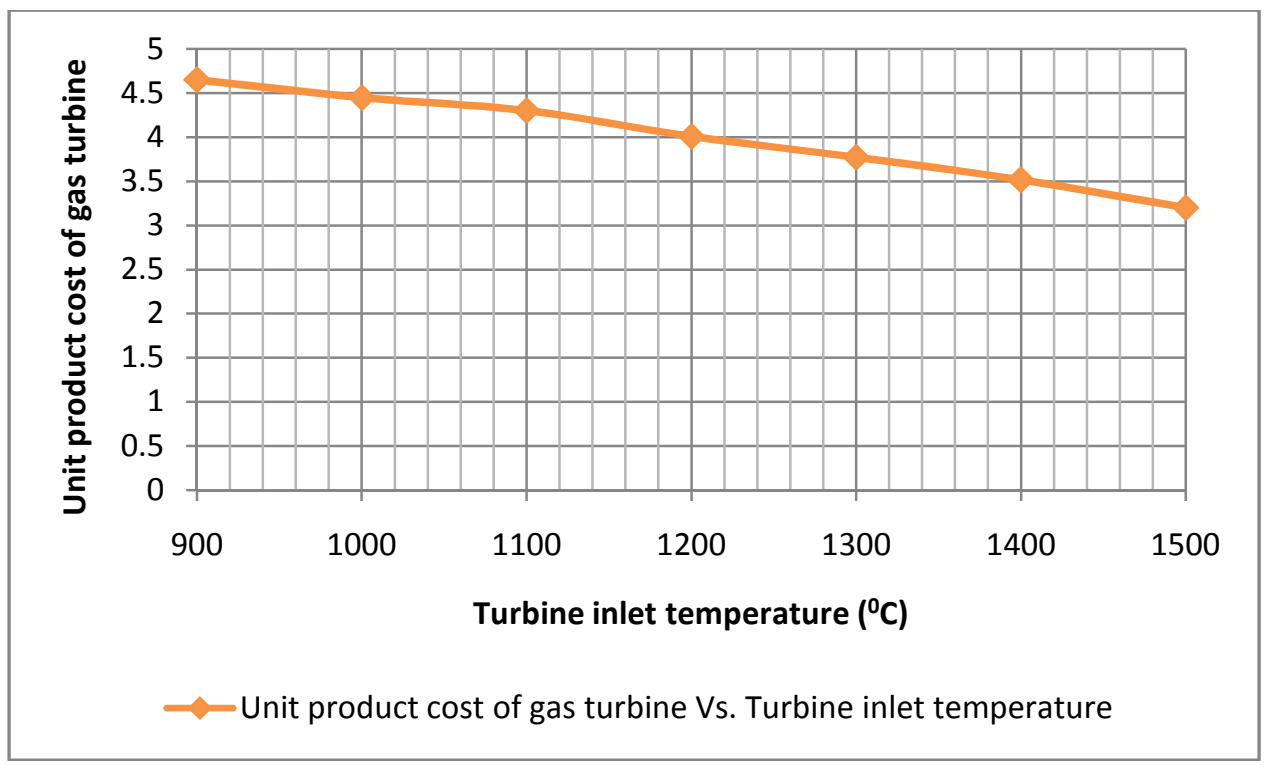

Fig. 6 Variation of unit product cost of gas turbine with turbine inlet temperature

Combining the results shown in Fig. 3 and Fig. 4, we find that whereas the unit product cost of the turbine system decreases with an increase in the inlet steam temperature, the unit product cost of boiler increases. Hence to arrive at the optimal value of inlet steam temperature, we combine the results of Fig. 4 and Fig. 5, to arrive at the optimal state. These results are shown in Fig. 7. 


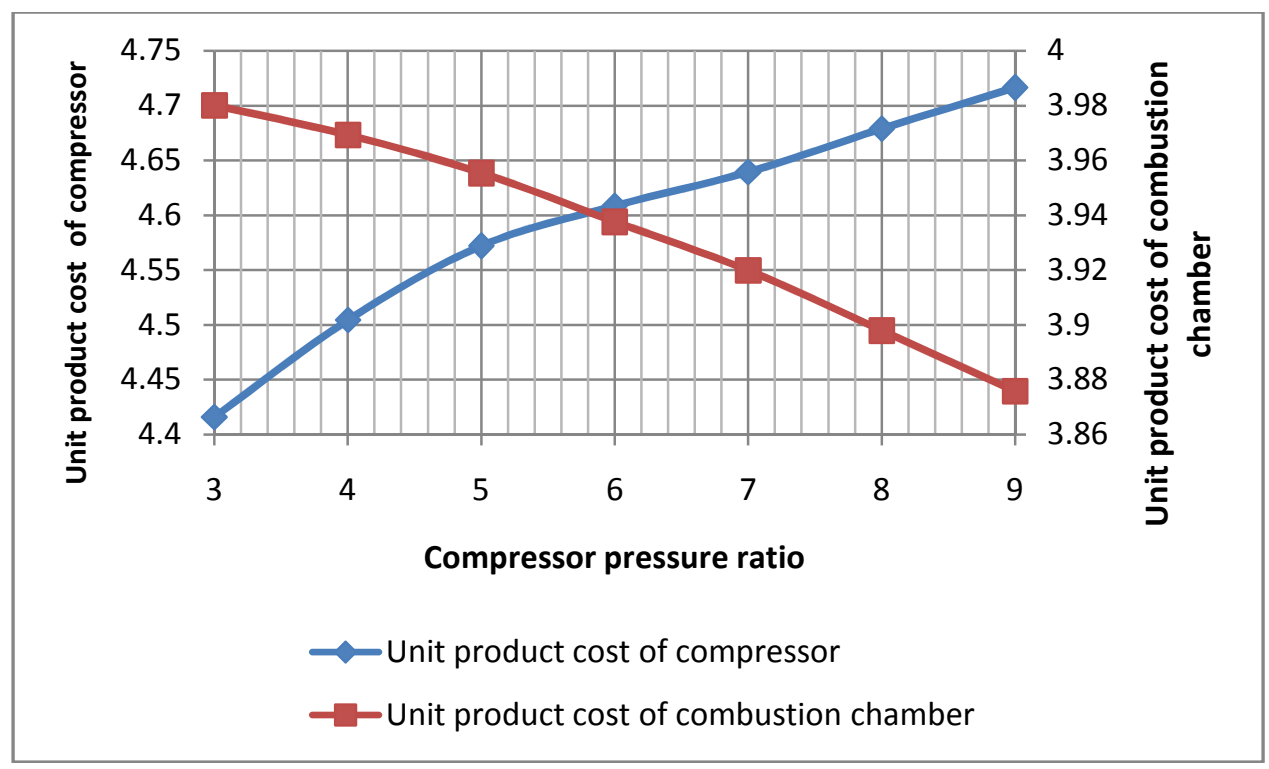

Fig. 7. Combined effect of compressor pressure ratio on unit product cost of compressor and combustion chamber

From Fig. 7 it can be seen that the optimal state occurs at compresor pressure ratio of 5.8 at which the unit product cost of the compressor is 4.6 US \$/ MW and the unit product cost of the combustion chamber is 3.94 US \$/ MW. If further reduction in unit product cost of the combustion chamber is to be achieved more money would have to be spent on employing higher compressor pressure ratios. Hence, the overall unit product cost of the power generation system would increase.

The following relations have been derived from the current study, which put forward the unit product cost of compressor and unit product cost of the combustion chamber as a function of compressor pressure ratio $(r)$.

$$
\begin{aligned}
& c_{\text {comp }}=4.3151\left(1.0103^{(r)}\right) \\
& c_{c c}=4.0402\left(0.9955^{(r)}\right)
\end{aligned}
$$

Combining the results shown in Fig. 5 and Fig. 6, we find that whereas the unit product cost of the combustion chamber increases with an increase in the turbine inlet temperature, the unit product cost of gas turbine system decreases. Hence to arrive at the optimal value of turbine inlet temperature, we combine the results of Fig. 5 and Fig. 6, to arrive at the optimal state. These results are shown in Fig. 8. 


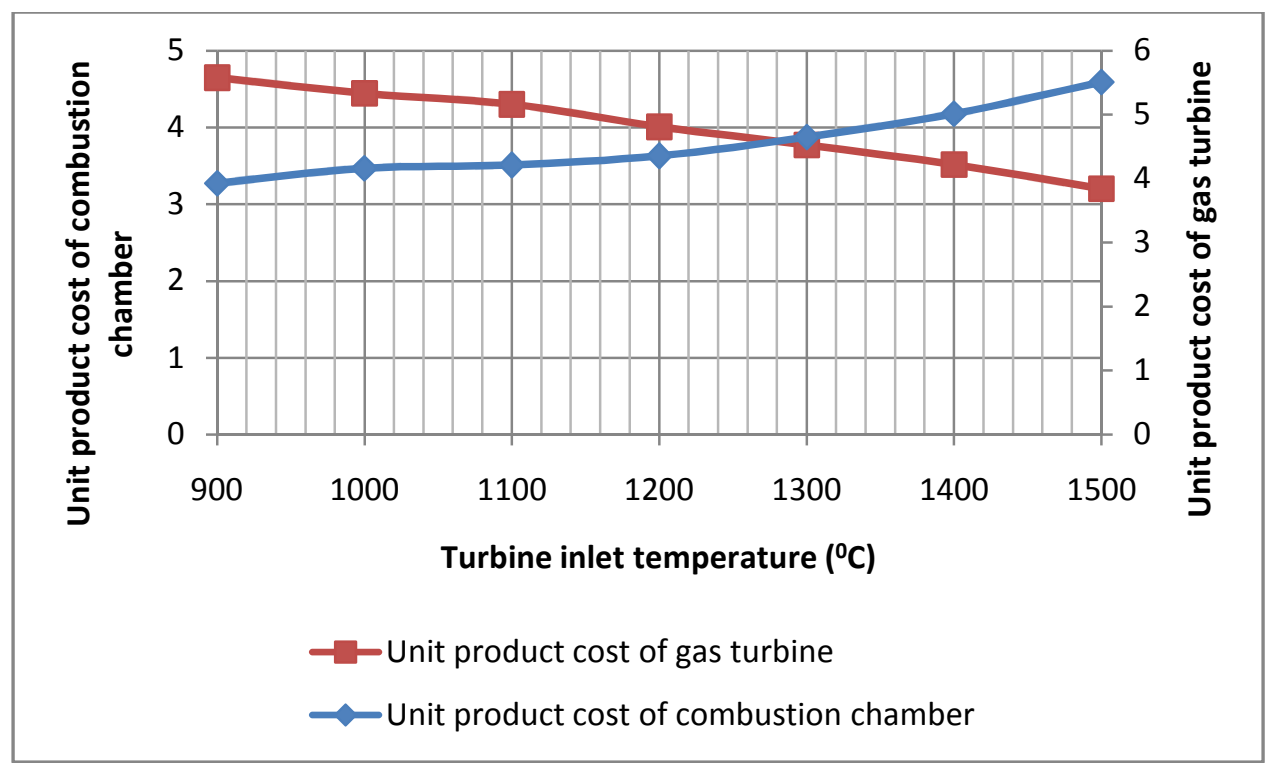

Fig. 8. Combined effect of turbine inlet temperature on unit product cost of combustion chamber and gas turbine

From Fig. 8 it can be seen that the optimal state occurs at turbine inlet temperature of $1280^{\circ} \mathrm{C}$ at which the unit product cost of the combustion chamber is 3.9 US \$/ MW and the unit product cost of the combustion chamber is 4.7 US \$/ MW. If further reduction in unit product cost of the gas turbine is to be achieved more money would have to be spent on higher turbine inlet temperatures. Hence, the overall unit product cost of the power generation system would increase.

The following relations have been derived from the current study, which put forward the unit product cost of combustion chamber and unit product cost of gas turbine as a function of turbine inlet temperature (TIT).

$$
\begin{aligned}
& c_{c c}=2.3863\left(1.0005^{(T I T)}\right) \\
& c_{g t}=8.2648\left(0.9994^{(T I T)}\right)
\end{aligned}
$$

\section{CONCLUSIONS}

This study puts forward a novel approach to analyze the performance of an open cycle gas turbine system. Compressor pressure ratio and turbine inlet temperature have major impact on the performance of open cycle gas turbine power plant. Variation in unit exergetic cost of gas turbine system, compressor and combustion chamber have been analyzed. This provides a basis for arriving at the optimal value of compressor pressure ratio and turbine inlet temperature.

Further exponential relations have been developed which prove very useful in calculating the values of the costs for the gas turbine system. This study provides an excellent basis for analyzing the performance of an open cycle gas turbine power plant. 
The limitation of current study is that all the factors which affect the performance of open cycle gas turbine power plant have not been considered. The current study forms the basis for future endeavors which may analyze the open cycle gas turbine system in greater detail. More factors can be considered in future analysis for better understanding of the open cycle gas turbine power plant.

\section{REFERENCES}

[1] Bejan A. (2002) Fundamentals of Exergy Analysis, Entropy Generation Minimization, and the Generation of Flow Architecture. International Journal of Energy Research, Vol. 26, No. 7, 545-565.

[2] Mishra R.D., Sahoo P.K., Gupta A. (2002) Application of exergetic cost theory to LiBr/H2O vapour absorption system. Energy, 1009-1025.

[3] Mishra R.D., Sahoo P.K., Gupta A. (2003) Thermoeconomic optimization of single effect water/ LiBr vapour absorption refrigeration system. International Journal of Refrigeration, 26, 158-169.

[4] Mishra R.D., Sahoo P.K. Gupta A. (2005) Thermoeconomic optimization of double effect water/ LiBr vapour absorption refrigeration system. International Journal of Refrigeration, 28, 331-343.

[5] Moran M.J. and Sciubba E. (1994) Exergy analysis: Principles and practice. Journal of Engineering for Gas Turbines and Power, 116, 285-290.

[6] Rosen M. (2002) Clarifying thermodynamic efficiencies and losses via exergy. Exergy International Journal, 2, 3-5.

[7] Rosen M. (2001) Editorial-Exergy in industry: Accepted or not?. Exergy, An International Journal, 2, 67.

[8] Rosen M. (2001) Energy and Exergy based comparison of coal fired and nuclear steam power plants. Exergy International Journal, 3, 180-192.

[9] Rosen M.: Energy crisis or exergy crisis? (2002) Exergy, An International Journal, 2, 125-127.

[10] Rosen M., Dincer I. (2003) Thermoeconomic Analysis of power plants: an application to a coal fired electrical generating station. Energy Conversion and Management, 44, 2743-2761.

[11] Horlock J.H., Young J.B., Manfrida G. (2000) Exergy Analysis of Modern Fossil- Fuel Power Plant. Journal of Engineering for Gas Turbines and Power, Vol. 122, 1 - 7 .

[12] Oktay Z. (2009) Investigation of coal-fired power plants in Turkey and a case study. Applied Thermal Energy, Vol. 29, 550-557.

[13] Jin H., Ishida M. , Kobayashi M., Nunokawa M.: Exergy Evaluation of Two Current Advanced Power Plants: Supercritical Steam Turbine and Combined Cycle (1997) Tranactions of ASME, Vol. 119 , pp $250-256$.

[14] Rosen M.A. (1999) Second-Law Analysis: Approaches and Implications. International Journal of Energy Research, 23, 415 - 429.

[15] Rosen M.A. (2002) Assessing Energy Technologies and Environmental Impacts with the Principles of Thermodynamics. Applied Energy, 72, 427 - 441.

[16] Rosen M.A., (2003) Exergy Methods for Assessing and Comparing Thermal Storage Systems. International Journal of Energy Research, 27(4), 415 - 430.

[17] Ganapathy T., Alagumurthi N., Gakkhar R. P., Murugesan K. (2009) Exergy Analysis of Operating Lignite Fired Thermal Power Plant. Journal of Engineering Science and Technology Review 2 (1), 123-130.

[18] Tsatsaronis G., Park M. (2002) On Avoidable and Unavoidable Exergy Destructions and Investment Costs in Thermal Systems. Energy Conversion \& Management, Vol. 43, No. 9-12, pp. 1259-1270.

[19] Som S.K., Datta A. (2008) Thermodynamic irreversibilities and exergy balance in combustion processes. Progress in Energy and Combustion Science 34, 351-376. 